\title{
Adsorption isotherms, kinetics and mechanism for the adsorption of cationic and anionic dyes onto carbonaceous particles prepared from Juglans regia shell biomass
}

\author{
S. Nethaji $\cdot$ A. Sivasamy $\cdot$ A. B. Mandal
}

Received: 4 November 2011/Revised: 25 May 2012/Accepted: 2 August 2012/Published online: 16 November 2012

(c) CEERS, IAU 2012

\begin{abstract}
In the present study, Juglans regia shells were used to prepare activated carbon by acid treatment method. $J$. regia shell-based activated carbon was used for the adsorption of two synthetic dyes namely, a basic dye malachite green and an acid dye amido black 10B. The prepared adsorbent was crushed and sieved to three different mesh sizes 100,600 and $1,000 \mu \mathrm{m}$. The adsorbent was characterized by scanning electron microscopy, surface acidity and zero-point charge. Batch experiments were carried out by varying the parameters like initial aqueous phase $\mathrm{pH}$, adsorbent dosage and initial dye concentration. The equilibrium data were tested with Langmuir, Freundlich, Redlich-Peterson and Sips isotherm at three different temperatures 293, 300 and $313 \mathrm{~K}$ and it was found that the Freundlich isotherm best fitted the adsorption of both the dyes. Kinetic data were tested with pseudo first-order model and pseudo second-order model. The mechanism for the adsorption of both the dyes onto the adsorbent was studied by fitting the kinetic data with intraparticle diffusion model and Boyd plot. External mass transfer was found to be the rate-determining step. Based on the ionic nature of the adsorbates, the extent of film diffusion and intraparticle diffusion varied; both being system specific. Thermodynamic parameters were also calculated. Finally, the process parameters of each adsorption system were compared to develop the understanding of the best suitable system.
\end{abstract}

Electronic supplementary material The online version of this article (doi:10.1007/s13762-012-0112-0) contains supplementary material, which is available to authorized users.

S. Nethaji · A. Sivasamy $(\bowtie) \cdot$ A. B. Mandal Chemical Engineering Area, CSIR-Central Leather Research Institute (Council of Scientific and Industrial Research), Adyar, Chennai 600020, India

e-mail: arumugamsivasamy@yahoo.co.in
Keywords Adsorption - Malachite green - Amido black · Intraparticle diffusion - Boyd plot

\section{Introduction}

Underground water is the major source of drinking water. This underground water is being polluted by the wastewater containing a large number of contaminants like acids, bases, toxic organics, inorganics, heavy metals (Repo et al. 2010), dissolved solids and colors disposed by leather and textile industries. Out of all such contaminants, color is the most visible pollutant and the presence of very minute quantity makes it undesirable for use. Some of the dyes are toxic, stable and non-biodegradable (Gupta et al. 2004). Thus, the removal of color from dye-bearing effluents becomes a major challenge due to the difficulty in treating such wastewaters by conventional treatment methods such as chemical and biological oxidation methods (Vadivelan and Vasanth kumar 2005). However, adsorption technique proved to be an efficient and economical process for the treatment of these dye-bearing effluents. But the efficiency of the process lies in choosing the suitable adsorbent. The chosen adsorbent should be easily available, cheap and should have no economic value. For the past two decades, a large variety of waste materials particularly from industrial and agricultural waste products, whose disposal has been a problem, have been successfully utilized as adsorbents for treating the industrial effluents (Bhatnagar and Sillanpaa 2010). Some common waste materials used for this purpose include rubber seed coat (Rengaraj et al. 2002), pecan shells (Shawabke et al. 2002), jute fiber (Senthilkumaar et al. 2005), Indian rosewood sawdust (Garg et al. 2004), olive stones (El-Sheikh et al. 2004), pine wood (Tsenga et al. 2003), coir pith (Namasivayam and Kavitha 2002), rice 
husk (Guo et al. 2005), bamboo (Hameed et al. 2007a), rattan sawdust (Hameed et al. 2007a) and oil palm fiber (Tan et al. 2007).

The present study is the thriving effort to utilize an agricultural waste biomass Juglans regia shell as adsorbent. J. regia is mainly used in food industries and its shell is thrown out as a waste product which is of no economical value. In the present study, this $J$. regia shells were carbonized and the activated carbon prepared from J. regia shells (JSAC) was used for the adsorption of two dyes namely malachite green (MG) and amido black 10B (AB). MG is a basic dye whereas, $A B$ is an acid dye. The significance of this study is to discuss the variation in mechanism of the adsorption processes based on the ionic nature of the adsorbates. This study was carried out from Jan, 2011 to May, 2011 at Central Leather Research Institute (CSIR-CLRI), Adyar, Chennai, India.

\section{Materials and methods}

\section{Preparation of JSAC}

J. regia shells used in the present study were procured from small scale food industries in Chennai, India and were crushed into small pieces. The crushed shells were washed with deionized water until all the leachable impurities were removed. Then the materials were dried in sunlight for $48 \mathrm{~h}$ to remove moisture. The dried shells were carbonized by treating with concentrated $\mathrm{H}_{2} \mathrm{SO}_{4}$ (1:1 ratio) for $48 \mathrm{~h}$. The carbonized $J$. regia shells were then washed with water until it became neutralized. Then the neutralized activated carbon was dried in a hot air oven at $140{ }^{\circ} \mathrm{C}$ for $48 \mathrm{~h}$. The dried $J$. regia shell-based activated carbon (JSAC) was then crushed and sieved to three mesh sizes $(100,600$ and $1,000 \mu \mathrm{m})$.

\section{Characterization of activated carbon}

The zero-point charge of the prepared activated carbon was determined by solid addition technique (Balistrieri and Murray 1981). The surface functionality of JSAC was evaluated by Boehm titration method (Boehm 1966) and the surface morphology of JSAC was studied by scanning electron microscope.

Preparation of adsorbate solutions

MG $\left(\mathrm{C}_{52} \mathrm{H}_{54} \mathrm{~N}_{4} \mathrm{O}_{12}\right)$ and $\mathrm{AB}$ 10B $\left(\mathrm{C}_{4} \mathrm{OH}_{28} \mathrm{~N}_{7} \mathrm{NaO}_{13} \mathrm{~S}_{4}\right)$ were purchased from $\mathrm{M} / \mathrm{s}$. s.d. fine chemicals and used without further purification. The stock solution $(1,000 \mathrm{mg} / \mathrm{L})$ of the dyes was prepared by dissolving accurately weighed amount of the dyes in distilled water. All working solutions of the desired concentrations were prepared by diluting the stock solutions with distilled water.

Analytical measurements

Unknown concentrations of the dyes were determined by finding out the absorbance at the characteristic wavelength using a double beam UV-visible spectrophotometer (Shimadzu UV-2102 PC). Standard calibration charts were prepared by measuring the absorbance of different dye concentrations at $(\lambda \max ) 619 \mathrm{~nm}$ for $\mathrm{AB}$ and $655 \mathrm{~nm}$ for MG and unknown concentrations of dyes before and after adsorption were computed from the calibration charts. The $\mathrm{pH}$ of the aqueous solutions was measured by Digisun Electronics System (Digital pH meter model 2001). Surface morphology of the activated carbon was studied by SEM of Hitachi make (model S-3400N).

Equilibrium experiments

Adsorption equilibrium experiments were carried out by varying the initial concentrations of dyes as $1,10,15,25$, $50,100,250,500,700$ and $1,000 \mathrm{mg} / \mathrm{L}$. The required amount of the adsorbent was added and the solutions were agitated for $24 \mathrm{~h}$ at $100 \mathrm{rpm}$ at $300 \mathrm{~K}$. The same experimental procedures were repeated at 293 and $313 \mathrm{~K}$.

The amount of adsorbed dyes at equilibrium, $q_{\mathrm{e}}(\mathrm{mg} / \mathrm{g})$ was calculated by (Repo et al. 2011a)

$q_{\mathrm{e}}=\frac{\left(C_{0}-C_{\mathrm{e}}\right) v}{w}$

where $C_{\mathrm{o}}$ and $C_{\mathrm{e}}(\mathrm{mg} / \mathrm{L})$ are the liquid phase initial and equilibrium concentrations of the dyes, respectively. $V$ is the volume of the solution $(L)$, and $W$ is the mass of dry adsorbent used ( $\mathrm{g}$ ).

Langmuir and Freundlich isotherm parameters were determined by fitting the data with linear regression analysis using Origin 7.0 software whereas non-linear regression analysis by Microsoft Office Excel 2007 solver was applied to estimate Sips and Redlich-Peterson isotherm parameters.

\section{Kinetic experiments}

The kinetics of adsorption of dyes onto JSAC was carried out by withdrawing and analyzing the samples at the time interval of every $5 \mathrm{~min}$ for the first $30 \mathrm{~min}$ and later at every 10 min until the consecutive residual dye concentrations became closer. The kinetic experiments were carried out separately for four different initial dye concentrations such as $25,50,75$ and $100 \mathrm{mg} / \mathrm{L}$ for all the three particle sizes at $300 \mathrm{~K}$. 
The amount of adsorption at time $t$ was calculated by (Bulut and Ozacar (2008)

$q_{\mathrm{t}}=\frac{\left(C_{0}-C_{\mathrm{t}}\right) v}{w}$

where $C_{0}$ and $C_{\mathrm{t}}(\mathrm{mg} / \mathrm{L})$ are the liquid phase concentrations of dyes at initial time and time $t$, respectively. $V$ is the volume of the solution $(L)$, and $W$ is the mass of dry adsorbent used (g).

\section{Results and discussions}

Characterization of the adsorbent

The surface acidity of JSAC was determined by Boehm titration method and the total surface acidity was calculated as $0.3503 \mathrm{meq}^{-1}$ with the maximum composition of phenolic group $\left(0.270871 \mathrm{meq}^{-1}\right)$, with traces of lactonic $\left(0.0321 \mathrm{meq}^{-1}\right)$ and carboxylic $\left(0.0473 \mathrm{meq} \mathrm{g}^{-1}\right)$ groups. The zero-point charge $\left(\mathrm{pH}_{\mathrm{zpc}}\right)$ was found to occur at $\mathrm{pH}$ 2.5. The surface morphology of the JSAC was studied by SEM and the images were displayed in Fig. 1. From these micrographs, pores and scale like structures are evident on the surface of the prepared activated carbon.
Influence of initial $\mathrm{pH}$

The adsorption of MG and $\mathrm{AB}$ onto JSAC were studied at different $\mathrm{pH}$ varying from 2.3 to 10.5 for all three particle sizes $(100,600$ and $1,000 \mu \mathrm{m})$. It was found that the maximum adsorption occurred at $\mathrm{pH}$ 6-7 for $\mathrm{MG}$ and at $\mathrm{pH}$ 2.3 for $\mathrm{AB}$ dye. The surface of the adsorbent will be negatively charged above $\mathrm{pH}_{\mathrm{zpc}}$ and positively charged below $\mathrm{pH}_{\mathrm{zpc}}$ (2.5) (Preethi and Sivasamy 2006). At low $\mathrm{pH}$, MG will get protonated as $-\mathrm{N}^{+}\left(\mathrm{CH}_{3}\right)_{2}$, and $\mathrm{H}^{+}$ions from the acidic solution compete with the positively charged dye molecules thus inhibiting the adsorption process. But, at $\mathrm{pH}$ range between 6 and 7 , the $\mathrm{H}^{+}$ions from the aqueous solution decreased and hence favouring the adsorption of protonated MG dyes onto the negatively charged adsorbent surface. Similar result was reported elsewhere by Hameed and El-Khaiary (2008). In case of azo dye AB, if the electrostatic interaction was the only step involved in the adsorption process, then, the $\%$ adsorption would have been maximum at $\mathrm{pH}$ ranging from 2.5 to 5.5 where the adsorbent surface will be negatively charged and the dye will be protonated as $-\mathrm{SO}_{3} \mathrm{H}$. But in the observed process, JSAC might have interacted with the dye molecules through hydrogen bonding and hydrophobic-hydrophobic mechanisms as reported elsewhere by Al-Degs et al. (2008).
Fig. 1 SEM micrograph of JSAC
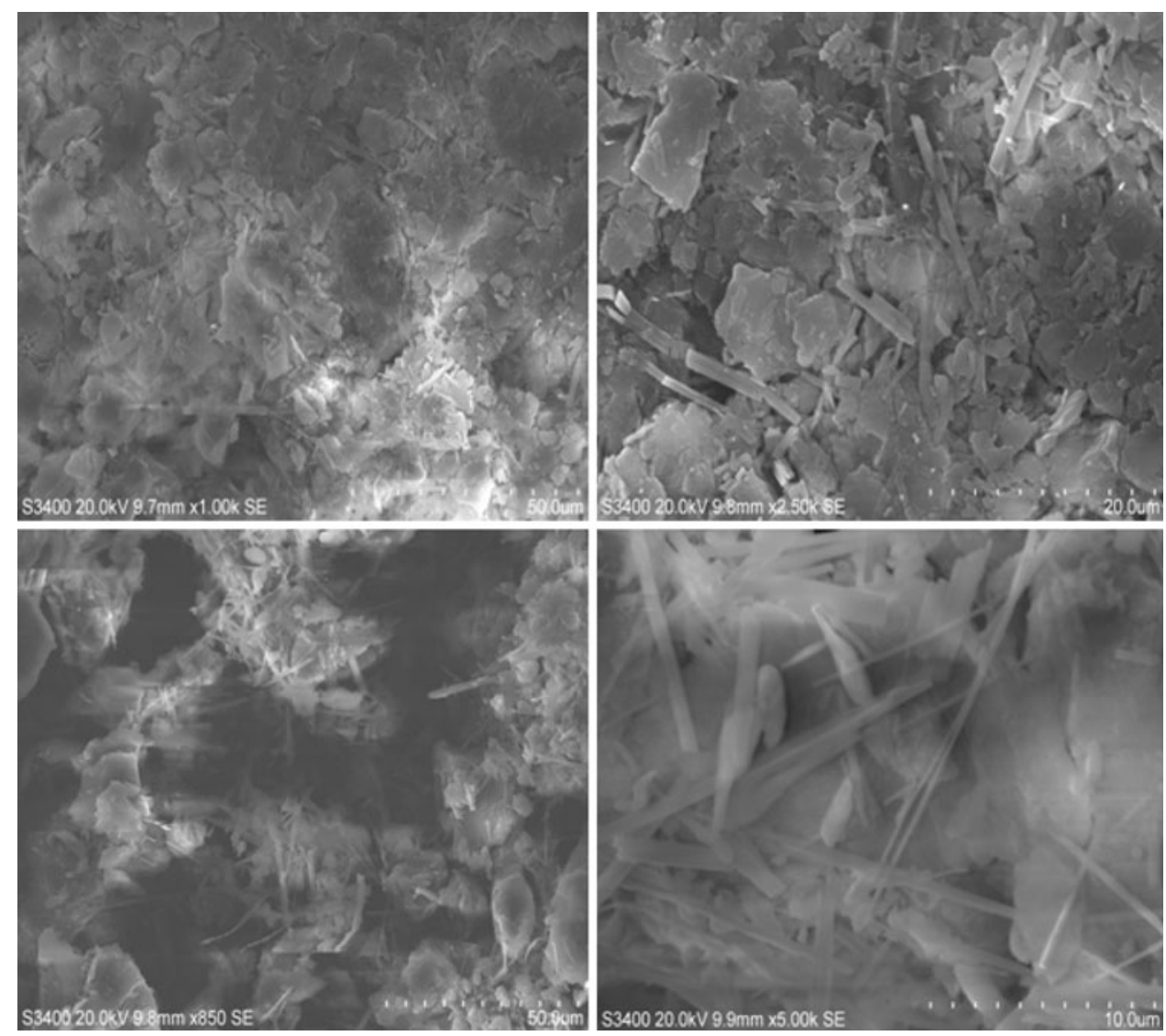
Hence the adsorption of $\mathrm{AB}$ onto JSAC was maximum at $\mathrm{pH} 2.3$. But the maximum $\%$ adsorption was observed to be higher for MG than $\mathrm{AB}$.

\section{Influence of adsorbent dosage}

Effect of variation of mass of JSAC was studied by increasing the adsorbent dosage from $0.001 / 10$ to $0.5 \mathrm{~g} / 10 \mathrm{~mL}$ for all the three particle sizes. The results showed that $\%$ adsorption of both dyes, either basic or acid, increased with the increase in the adsorbent dosage. The increase in adsorbent dosage appeared to promote more active sites, which facilitates the adsorption of dyes. However, for the adsorption of $\mathrm{MG}$, the $\%$ adsorption decreased after certain point. This may be due to the decrease in total adsorption surface area available to MG resulting from overlapping or aggregation of adsorption sites (Zhang et al. 2008). It was found that $3 \mathrm{~g} / \mathrm{L}$ of JSAC adsorbed $100 \%$ of $25 \mathrm{mg} / \mathrm{L}$ of $\mathrm{MG}$ whereas the same amount of JSAC could adsorb only around $90 \%$ of $25 \mathrm{mg} / \mathrm{L}$ of AB. Since JSAC was acid treated, it contained more acidic functional groups on its surface. The basic dye MG had a good affinity toward the acidic adsorbent surface when compared to the acid dye AB. Hence the \% adsorption of MG was higher than AB.

\section{Effect of initial dye concentration at different} temperatures

The effect of initial dye concentrations was studied for both the dyes by varying the dye concentrations as $1,10,15,25$, $50,100,250,500,700$ and 1,000 mg/L at different temperatures 293,300 and $313 \mathrm{~K}$ and the result suggested that the $\%$ adsorption decreased with the increase in initial dye concentrations for both the dyes. Furthermore, adsorption increased with an increase in temperature for both the dyes, indicating that the processes were endothermic.

\section{Adsorption equilibrium}

To optimize the design of the adsorption processes, it is important to establish the most appropriate correlation for the equilibrium curves. Various isotherms such as Langmuir, Freundlich, Sips and Redlich-Peterson isotherms had been used to evaluate the equilibrium characteristics of the adsorption processes. The parameters of the isotherm equations were calculated by linear regression analysis. The calculated adsorption parameters and the correlation coefficient $\left(r^{2}\right)$ for all the isotherms at 293, 300 and $313 \mathrm{~K}$ for all the three particle sizes of JSAC for the adsorption of MG and $\mathrm{AB}$ onto JSAC are summarized in Tables 1, 2.
Langmuir isotherm

The Langmuir equation is applicable to homogeneous adsorption where the adsorption of each adsorbate molecule on to the surface has equal sorption activation energy. The linear form of this isotherm is represented by the expression (Langmuir 1916):

$\frac{1}{q_{\mathrm{e}}}=\frac{1}{q_{\mathrm{m}} K_{\mathrm{L}} C_{\mathrm{e}}}+\frac{1}{q_{\mathrm{m}}}$

where $q_{\mathrm{e}}(\mathrm{mg} / \mathrm{g})$ and $C_{\mathrm{e}}(\mathrm{mg} / \mathrm{L})$ are the amount of adsorbed adsorbate per unit weight of adsorbent and unadsorbed adsorbate concentration in solution at equilibrium, respectively. The constant $K_{\mathrm{L}}(\mathrm{L} / \mathrm{g})$ is the Langmuir equilibrium constant and $q_{\mathrm{m}}$ is the theoretical monolayer saturation capacity.

The essential feature of the Langmuir isotherm can be expressed in terms of a dimensionless constant called separation factor $\left(R_{\mathrm{L}}\right.$, also called equilibrium parameter) which is defined by the following equation:

$R_{\mathrm{L}}=\frac{1}{1+K_{\mathrm{L}} C_{0}}$

where $C_{0}(\mathrm{mg} / \mathrm{L})$ is the initial adsorbate concentration. The value of $R_{\mathrm{L}}$ indicates the shape of the isotherms to be either unfavorable $\left(R_{\mathrm{L}}>1\right)$, linear $\left(R_{\mathrm{L}}=1\right)$, favorable $\left(0<R_{\mathrm{L}}<1\right)$ or irreversible $\left(R_{\mathrm{L}}=0\right)$.

The equilibrium data for the adsorption of both the dyes at all three temperatures for all the three particle sizes (100, 600 and 1,000 $\mu \mathrm{m}$ ) were fitted with the Langmuir isotherm. It can be inferred from Table 1 that the monolayer saturation capacity $\left(q_{\mathrm{m}}\right)$ and the Langmuir constant $\left(K_{\mathrm{L}}\right)$ increased with the increase in temperature (Mittal 2006) and decreased with the increase in the particle sizes of the adsorbent (Patil et al. 2011). It can also be found that the values of $q_{\mathrm{m}}$ and $K_{\mathrm{L}}$ were higher for the adsorption of MG than AB. This was because; values of $q_{\mathrm{m}}$ and $K_{\mathrm{L}}$ are directly proportional to $\%$ adsorption. Since decrease in the particle size of the adsorbent and the increase in temperature favors $\%$ adsorption, the values of $\mathrm{q}_{\mathrm{m}}$ and $K_{\mathrm{L}}$ increased. It was also found that the separation factor $\left(R_{\mathrm{L}}\right)$ was between 0 and 1 for both the dyes for all the three particle sizes indicating that the adsorption processes were favorable.

\section{Freundlich isotherm}

The most important multisite adsorption isotherm for heterogeneous surfaces is the Freundlich adsorption isotherm and the linear form of this isotherm is expressed as (Freundlich 1906):

$\log q_{\mathrm{e}}=\log K_{\mathrm{F}}+\frac{1}{n} \log C_{\mathrm{e}}$ 


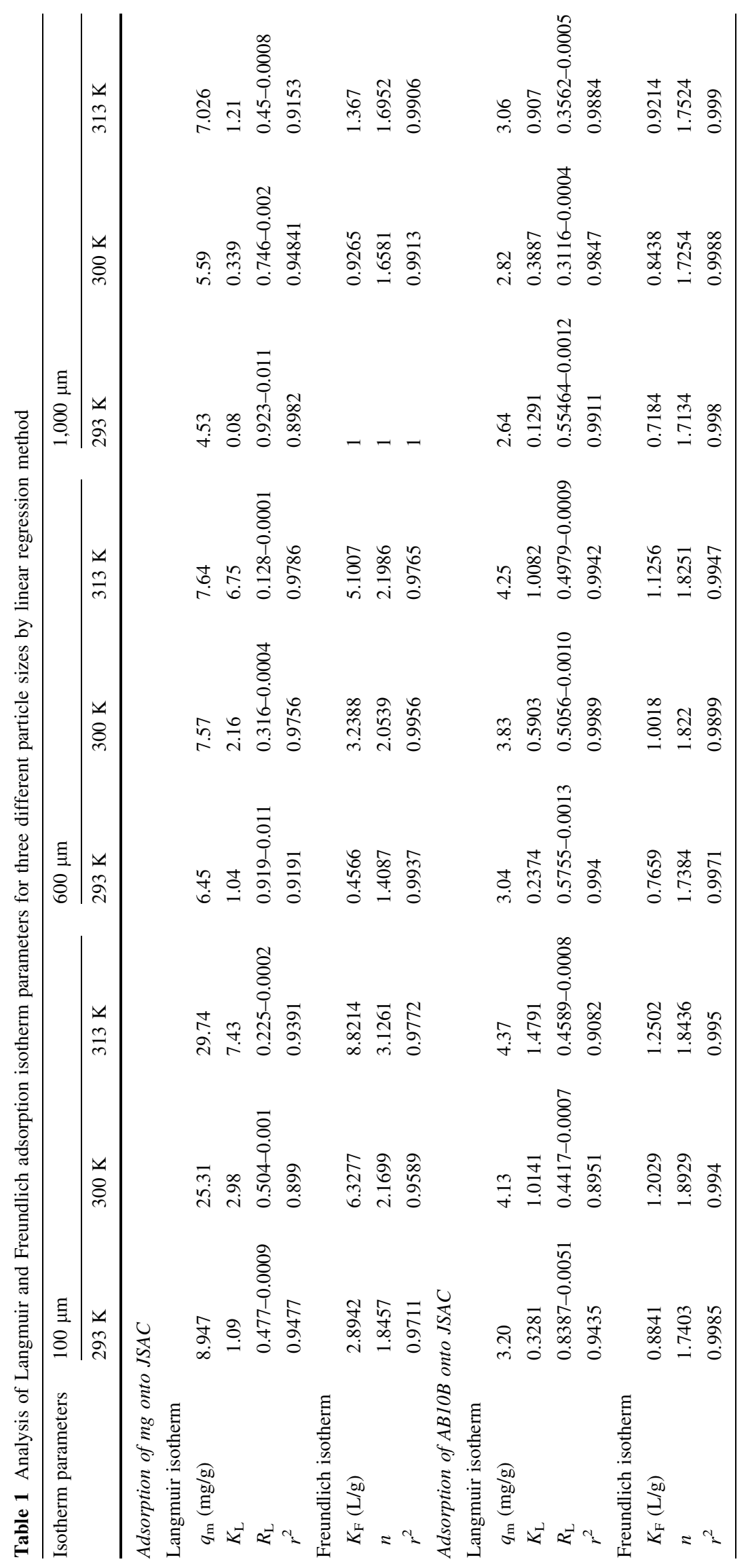


Table 2 Analysis of Sips and Redlich-Peterson adsorption isotherm parameters for three different particle sizes by non-linear regression method

\begin{tabular}{|c|c|c|c|c|c|c|c|c|c|}
\hline \multirow[t]{2}{*}{ Isotherm parameters } & \multicolumn{3}{|c|}{$100 \mu \mathrm{m}$} & \multicolumn{3}{|l|}{$600 \mu \mathrm{m}$} & \multicolumn{3}{|c|}{$1,000 \mu \mathrm{m}$} \\
\hline & $293 \mathrm{~K}$ & $300 \mathrm{~K}$ & $313 \mathrm{~K}$ & $293 \mathrm{~K}$ & $300 \mathrm{~K}$ & $313 \mathrm{~K}$ & $293 \mathrm{~K}$ & $300 \mathrm{~K}$ & $313 \mathrm{~K}$ \\
\hline \multicolumn{10}{|c|}{ Adsorption of $M G$ onto JSAC } \\
\hline \multicolumn{10}{|c|}{ Redlich-Peterson isotherm } \\
\hline$q_{\mathrm{m}}(\mathrm{mg} / \mathrm{g})$ & 8.11 & 24.84 & 25.82 & 6.07 & 7.38 & 7.71 & 4.29 & 5.93 & 6.99 \\
\hline$K_{\mathrm{KR}}$ & 1.25 & 3.02 & 8.29 & 2.78 & 3.82 & 5.72 & 3.62 & 4.62 & 1.19 \\
\hline$N_{\mathrm{KR}}$ & 0.18 & 0.39 & 0.16 & 0.42 & 0.29 & 0.39 & 0.41 & 0.53 & 0.41 \\
\hline$\chi^{2}$ & 0.232 & 0.422 & 1.453 & 2.634 & 12.432 & 0.344 & 1.323 & 5.322 & 5.432 \\
\hline \multicolumn{10}{|l|}{ Sips isotherm } \\
\hline$q_{\mathrm{m}}(\mathrm{mg} / \mathrm{g})$ & 12.54 & 30.18 & 35.72 & 11.94 & 14.82 & 16.82 & 10.82 & 12.75 & 19.73 \\
\hline$K_{\mathrm{S}}$ & 3.92 & 4.02 & 4.92 & 1.15 & 3.28 & 4.97 & 1.06 & 1.26 & 1.47 \\
\hline$n_{\mathrm{S}}$ & 0.38 & 0.48 & 0.51 & 0.16 & 0.29 & 0.42 & 0.38 & 0.27 & 0.11 \\
\hline$\chi^{2}$ & 2.233 & 1.343 & 12.453 & 23.42 & 12.42 & 0.432 & 2.435 & 1.343 & 0.435 \\
\hline \multicolumn{10}{|c|}{ Adsorption of $A B 10 B$ onto JSAC } \\
\hline \multicolumn{10}{|c|}{ Redlich-Peterson isotherm } \\
\hline$q_{\mathrm{m}}(\mathrm{mg} / \mathrm{g})$ & 3.01 & 3.92 & 4.29 & 2.98 & 3.63 & 4.11 & 2.58 & 2.61 & 2.99 \\
\hline$K_{\mathrm{KR}}$ & 0.86 & 1.02 & 1.26 & 0.62 & 0.68 & 1.01 & 0.16 & 0.29 & 0.94 \\
\hline$N_{\mathrm{KR}}$ & 0.28 & 0.36 & 0.18 & 0.51 & 0.29 & 0.39 & 0.32 & 0.11 & 0.42 \\
\hline$\chi^{2}$ & 1.343 & 14.432 & 0.422 & 32.422 & 0.432 & 3.12 & 23.334 & 0.12 & 2.41 \\
\hline \multicolumn{10}{|l|}{ Sips isotherm } \\
\hline$q_{\mathrm{m}}(\mathrm{mg} / \mathrm{g})$ & 7.92 & 8.03 & 10.98 & 4.82 & 9.28 & 12.85 & 5.02 & 6.72 & 7.08 \\
\hline$K_{\mathrm{S}}$ & 0.78 & 0.94 & 1.05 & 0.62 & 0.92 & 1.07 & 0.69 & 0.74 & 0.85 \\
\hline$n_{\mathrm{S}}$ & 0.41 & 0.29 & 0.41 & 0.49 & 0.27 & 0.32 & 0.29 & 0.52 & 0.39 \\
\hline$\chi^{2}$ & 10.83 & 25.92 & 11.73 & 14.63 & 25.98 & 11.73 & 17.38 & 1.43 & 0.51 \\
\hline
\end{tabular}

where $K_{\mathrm{F}}(\mathrm{L} / \mathrm{g})$ is the Freundlich constant and $n(\mathrm{~g} / \mathrm{L})$ is the Freundlich exponent. Therefore, a plot of $\log q_{\mathrm{e}}$ versus $\log$ $C_{\mathrm{e}}$ enables the constant and exponent $\mathrm{n}$ to be determined.

Freundlich isotherm was tested for both the dyes at the three temperatures for all the three adsorbent particle sizes. From Table 1, it was found that the Freundlich exponent $(n)$ and Freundlich constant $\left(K_{\mathrm{F}}\right)$ increased with the increase in temperature and decrease in the adsorbent particle sizes. It was also inferred that the values of $n$ and $K_{\mathrm{F}}$ were higher for the adsorption of MG than AB. Here the value of $n$ was between 1 and 10 which again proved that the processes are favorable at all the temperature for all three particle sizes.

Sips isotherm

The Sips isotherm is a combination of the Langmuir and Freundlich isotherms and can be derived using either equilibrium or thermodynamic approach (Repo et al. 2011a).

$q_{\mathrm{e}}=\frac{q_{\mathrm{m}}\left(K_{\mathrm{RP}} C_{\mathrm{e}}\right)^{n_{S}}}{1+\left(K_{\mathrm{RP}} C_{\mathrm{e}}\right)^{n_{\mathrm{RP}}}}$

where $K_{\mathrm{S}}(\mathrm{L} / \mathrm{mg})$ is the affinity constant and $n_{\mathrm{S}}$ describes the surface heterogeneity. When $n_{S}$ equals unity, the Sips isotherm returns to the Langmuir isotherm and predicts homogeneous adsorption. On the other hand, deviation of $n_{\mathrm{S}}$ value from the unity indicates heterogeneous surface.

Adsorption data of both the dyes onto JSAC were tested with Sips isotherm and the parameters obtained are given in Table 2. The Sips isotherm constants increased with the increase in temperature and decrease in particle size. Also $n_{\mathrm{S}}$ deviated widely from unity which again denotes the heterogeneity of the surface of the adsorbent.

Redlich-Peterson isotherm

The Redlich-Peterson isotherm combines the features of Langmuir and Freundlich isotherms. It can be represented as (Repo et al. 2011a):

$q_{\mathrm{e}}=\frac{q_{\mathrm{m}}\left(K_{\mathrm{RP}} C_{\mathrm{e}}\right)}{1+\left(K_{\mathrm{RP}} C_{\mathrm{e}}\right)^{n_{\mathrm{RP}}}}$

where $K_{\mathrm{RP}}(\mathrm{L} / \mathrm{mg})$ and $n_{\mathrm{RP}}$ are Redlich-Peterson constants. Redlich-Peterson isotherm parameters are similar to that of Sips isotherm parameters.

Redlich-Peterson isotherm was also used to fit the equilibrium data of the adsorption of $\mathrm{MG}$ and $\mathrm{AB}$ onto 
Table 3 Adsorption kinetic parameters

\begin{tabular}{|c|c|c|c|c|c|c|c|c|c|c|c|c|}
\hline \multirow{2}{*}{$\begin{array}{l}\text { Kinetic model } \\
\text { parameters }\end{array}$} & \multicolumn{4}{|l|}{$100 \mu \mathrm{m}$} & \multicolumn{4}{|c|}{$600 \mu \mathrm{m}$} & \multicolumn{4}{|c|}{$1,000 \mu \mathrm{m}$} \\
\hline & $\begin{array}{l}25 \\
\mathrm{mg} / \mathrm{L}\end{array}$ & $\begin{array}{l}50 \\
\mathrm{mg} / \mathrm{L}\end{array}$ & $\begin{array}{l}75 \\
\mathrm{mg} / \mathrm{L}\end{array}$ & $\begin{array}{l}100 \\
\mathrm{mg} / \mathrm{L}\end{array}$ & $\begin{array}{l}25 \\
\mathrm{mg} / \mathrm{L}\end{array}$ & $\begin{array}{l}50 \\
\mathrm{mg} / \mathrm{L}\end{array}$ & $\begin{array}{l}75 \\
\mathrm{mg} / \mathrm{L}\end{array}$ & $\begin{array}{l}100 \\
\mathrm{mg} / \mathrm{L}\end{array}$ & $\begin{array}{l}25 \\
\mathrm{mg} / \mathrm{L}\end{array}$ & $\begin{array}{l}50 \\
\mathrm{mg} / \mathrm{L}\end{array}$ & $\begin{array}{l}75 \\
\mathrm{mg} / \mathrm{L}\end{array}$ & $\begin{array}{l}100 \\
\mathrm{mg} / \mathrm{L}\end{array}$ \\
\hline \multicolumn{13}{|c|}{ Adsorption of $M G$ onto JSAC } \\
\hline \multicolumn{13}{|c|}{ Pseudo first-order model } \\
\hline$k_{1}(1 / \min )$ & 0.5051 & 0.2334 & 0.2065 & 0.239 & 0.193 & 0.0954 & 0.0822 & 0.0619 & 0.0678 & 0.0348 & 0.0327 & 0.0289 \\
\hline$q_{\mathrm{e}}(\mathrm{mg} / \mathrm{g})$ & 0.6342 & 0.8184 & 2.1679 & 8.9182 & 7.6668 & 5.7017 & 17.8749 & 19.2574 & 3.7013 & 5.8784 & 10.3119 & 13.6549 \\
\hline$r^{2}$ & 1 & 0.9612 & 0.9569 & 0.9726 & 0.9644 & 0.8421 & 0.973 & 0.9703 & 0.8768 & 0.9859 & 0.9366 & 0.9184 \\
\hline \multicolumn{13}{|c|}{ Pseudo second-order model } \\
\hline$k_{2}(\mathrm{~g} / \mathrm{mg} \min )$ & 2.75 & 0.5246 & 0.17773 & 0.0617 & 0.0365 & 0.0254 & 0.0058 & 0.0022 & 0.0252 & 0.0071 & 0.0022 & 0.0014 \\
\hline$q_{\mathrm{e}}(\mathrm{mg} / \mathrm{g})$ & 2.5282 & 5.0684 & 7.6511 & 10.3626 & 3.0703 & 5.5096 & 12.4069 & 13.2978 & 2.6041 & 5.2438 & 8.9928 & 11.8063 \\
\hline$r^{2}$ & 0.9999 & 0.9999 & 0.9998 & 0.9992 & 0.9955 & 0.9982 & 0.9943 & 0.98 & 0.9914 & 0.9939 & 0.9747 & 0.985 \\
\hline \multicolumn{13}{|c|}{ Intraparticle diffusion model } \\
\hline $\mathrm{k}_{\mathrm{i}}\left(\mathrm{mg} / \mathrm{g} \min ^{1 / 2}\right)$ & 0.0319 & 0.1023 & 0.2292 & 0.4772 & 0.3246 & 0.3927 & 0.8719 & 0.9576 & 0.1853 & 0.3023 & 0.5081 & 0.6396 \\
\hline$C$ & 0.077 & 0.103 & 0.274 & 0.572 & 0.551 & 0.743 & 0.942 & 1.183 & 0.584 & 0.921 & 1.034 & 1.324 \\
\hline \multicolumn{13}{|c|}{ Adsorption of $A B 10 B$ onto JSAC } \\
\hline \multicolumn{13}{|c|}{ Pseudo first-order model } \\
\hline$k_{1}(1 / \mathrm{min})$ & 0.2661 & 0.1464 & 0.1025 & 0.0577 & 0.061 & 0.0665 & 0.0368 & 0.026 & 0.0735 & 0.0383 & 0.026 & 0.0238 \\
\hline$q_{\mathrm{e}}(\mathrm{mg} / \mathrm{g})$ & 8.6175 & 10.6642 & 13.8101 & 9.4111 & 1.8266 & 4.7077 & 4.694 & 5.1008 & 2.2875 & 3.1096 & 5.699 & 5.6916 \\
\hline$r^{2}$ & 0.99628 & 0.9459 & 0.9686 & 0.987 & 0.9968 & 0.9981 & 0.9924 & 0.9792 & 0.9913 & 0.9964 & 0.9675 & 0.9913 \\
\hline \multicolumn{13}{|c|}{ Pseudo second-order model } \\
\hline$k_{2}(\mathrm{~g} / \mathrm{mg} \min )$ & 0.0579 & 0.0136 & 0.0093 & 0.0066 & 0.0457 & 0.0168 & 0.0112 & 0.0075 & 0.0495 & 0.0179 & 0.006 & 0.0063 \\
\hline$q_{\mathrm{e}}(\mathrm{mg} / \mathrm{g})$ & 2.5549 & 5.1679 & 6.9252 & 8.6132 & 2.386 & 4.4642 & 6.1538 & 7.8492 & 2.2011 & 4.1684 & 6.0679 & 7.55585 \\
\hline$r^{2}$ & 0.996 & 0.9922 & 0.9958 & 0.99965 & 0.9993 & 0.9977 & 0.9996 & 0.9991 & 0.999 & 0.9998 & 0.9998 & 0.9995 \\
\hline \multicolumn{13}{|c|}{ Intraparticle diffusion model } \\
\hline$k_{\mathrm{i}}\left(\mathrm{mg} / \mathrm{g} \min ^{1 / 2}\right)$ & 0.2817 & 0.5179 & 0.5582 & 0.5852 & 0.1628 & 0.3134 & 0.3101 & 0.3705 & 0.1236 & 0.2093 & 0.3147 & 0.3388 \\
\hline$C$ & 0.568 & 0.5207 & 1.1326 & 1.7113 & 0.7842 & 1.0779 & 2.0317 & 2.4952 & 0.8391 & 1.193 & 1.374 & 2.2129 \\
\hline
\end{tabular}

JSAC. Redlich-Peterson isotherm constants also varied in the same fashion as that of the Sips isotherm constants. The parameters for Redlich-Peterson isotherm for all the three particle sizes at three temperatures are given in Table 2.

By testing with both the isotherm models, it can be inferred that the value of separation factor $\left(R_{\mathrm{L}}\right)$ fell between 0 and 1 and the value of the Freundlich exponent (n) from the Freundlich isotherm was between 1 and 10 which proved that the conducted adsorption processes were favorable. Both these adsorption processes followed the Freundlich isotherm since the $r^{2}$ values were closer. Further Redlich-Peterson and Sips isotherm constants $\left(n_{\mathrm{RP}}\right.$ and $n_{\mathrm{S}}$ ) also confirmed that the surface of the prepared adsorbent was heterogeneous in nature.

\section{Adsorption kinetics}

The kinetic studies were carried out by withdrawing and analyzing the samples at the time interval of every $5 \mathrm{~min}$ for the first $30 \mathrm{~min}$ and later at every $10 \mathrm{~min}$ until the consecutive residual dye concentrations became closer.
The kinetic data for the adsorption of $\mathrm{MG}$ and $\mathrm{AB}$ onto JSAC of three different particle sizes with the four initial dye concentrations $(25,50,75$ and $100 \mathrm{mg} / \mathrm{L})$ were tested with the well-known kinetic models namely pseudo firstorder model and pseudo second-order model. The mechanism of the adsorption processes were studied by plotting the data with intraparticle diffusion model and Boyd plot. The parameters of these kinetic models are given in Table 3.

Pseudo first-order equation

Lagergren proposed a method for adsorption analysis namely pseudo first-order kinetic equation. The linear form of this equation is (Santhy and Selvapathy 2006)

$\ln \left(q_{\mathrm{e}}-q_{\mathrm{t}}\right)=\ln q_{\mathrm{e}}-k_{1} t$

where $q_{\mathrm{e}}(\mathrm{mg} / \mathrm{g})$ and $q_{\mathrm{t}}(\mathrm{mg} / \mathrm{g})$ are the amounts of adsorbed adsorbate at equilibrium and at time $t$, respectively, and $k_{1}\left(\mathrm{~min}^{-1}\right)$ is the rate constant of pseudo first-order adsorption. 
As seen from Table 3, the pseudo first-order rate constant $k_{1}$ increased with the decrease in the dye concentrations (Abechi et al. 2011) and decreased with the increase in particle size of the adsorbent (Ho and McKay 1988) for both the studied adsorption processes. It was also evident that there was a considerable difference between calculated $q_{\mathrm{e}}$ values and the experimental $q_{\mathrm{e}}$. The values of $k_{1}$ were found to be slightly higher for the adsorption of MG than $\mathrm{AB}$.

Pseudo second-order equation

The sorption kinetics can also be described by pseudo second-order model. The linear form of pseudo secondorder equation is expressed as (Bulut and Ozacar 2008).

$\frac{t}{q_{\mathrm{t}}}=\frac{1}{k_{2} q_{\mathrm{e}}^{2}}+\frac{1}{q_{\mathrm{e}}} t$

where $k_{2}(\mathrm{~g} / \mathrm{mg} \min )$ is the equilibrium rate constant of pseudo second-order adsorption. Equation (9) does not have the problem of assigning an effective $q_{\mathrm{e}}$. If the pseudo second-order kinetic equation is applicable, the plot of $t / q_{\mathrm{t}}$ against $t$ should give a linear relationship, from which $q_{\mathrm{e}}$ and $k_{2}$ can be determined from the slope and intercept of the plot.

From Table 3, it was clear that the pseudo second-order constant $k_{2}$ decreased with the increase in the dye concentration and also increased with the decrease in particle size of the adsorbent for both the adsorption processes. From this table it can also be found that the calculated $q_{\mathrm{e}}$ values were on par with the experimental $q_{\mathrm{e}}$ values for both the observed processes unlike the pseudo first-order equation. But the value of $k_{2}$ was found to vary in the same fashion as the value of $k_{1}$ of pseudo first-order model.

Intraparticle diffusion model

The intraparticle diffusion equation is given as (Cheung et al. 2007):

$q_{\mathrm{t}}=k_{\mathrm{i}} t^{\frac{1}{2}}+c$

where $q_{\mathrm{t}}$ is the amount of solute on the surface of the sorbent at time $t(\mathrm{mg} / \mathrm{g})$ and $k_{\mathrm{i}}$ is the intraparticle diffusion rate constant $\left(\mathrm{mg} / \mathrm{g} \min ^{1 / 2}\right)$. When intraparticle diffusion alone is the rate limiting step, then the plot of $q_{\mathrm{t}}$ versus $t^{1 / 2}$ passes through the origin. When film diffusion is also taking place then the intercept is $\mathrm{C}$, which gives the idea on the thickness of the boundary layer.

From the intraparticle diffusion plots shown in Figs. 2 and 3 , it was evident that the adsorption processes followed two steps. The first linear portion followed the boundary layer diffusion followed by another linear portion which represents the intra particle diffusion. This shows that the

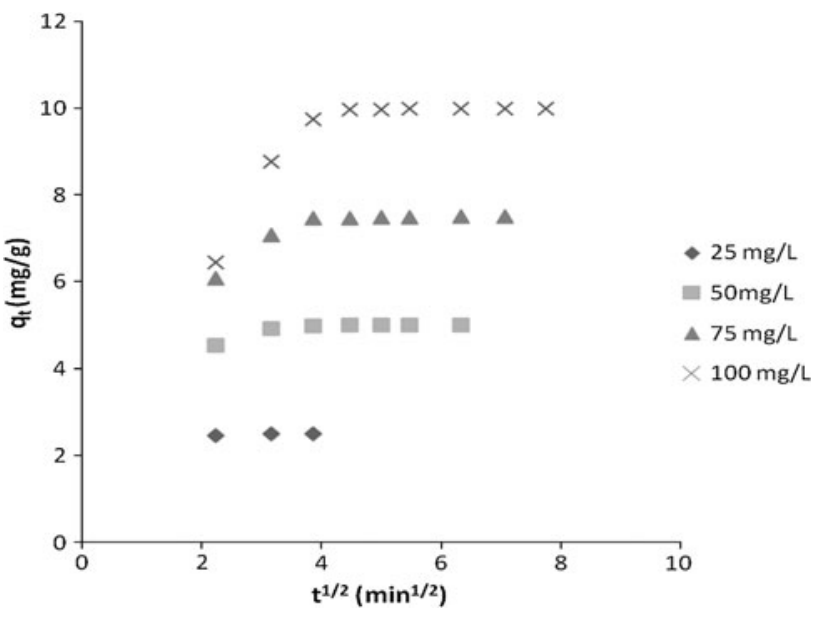

Fig. 2 Intraparticle diffusion model for the adsorption of $\mathrm{MG}$ onto JSAC for $100 \mu \mathrm{m}$ (ads. dosage $=1.5 \mathrm{~g} / 150 \mathrm{ml}$; $\mathrm{pH} 6.87 ; T=300 \mathrm{~K}$; agitation $=150 \mathrm{rpm}$ )

adsorption processes were not only by intraparticle diffusion but the film diffusion also played a role in both the observed processes (Vasanth kumar et al. 2005).

Boyd plot

The Boyd plot predicts the actual slow step involved in the adsorption process. The Boyd kinetic expression is given by (Vadivelan and Vasanth kumar 2005)

$F=1-(6 / \pi(22) 2) \exp \left(-\mathrm{B}_{\mathrm{t}}\right)$

and

$F=q_{\mathrm{t}} / q_{0}$

where $q_{0}$ is the amount of adsorbates adsorbed at infinite time $(\mathrm{mg} / \mathrm{g})$ and $q_{\mathrm{t}}$ represents the amount of dyes adsorbed at any time $t(\mathrm{~min}), F$ represents the fraction of solute adsorbed at any time $t$, and $B_{\mathrm{t}}$ is a mathematical function of $F$.

Substituting Eq. 10 in Eq. 9,

$1-F=(6 / \pi(24) 2) \exp \left(-\mathrm{B}_{\mathrm{t}}\right)$

or

$B_{\mathrm{t}}=-0.4977-\ln (1-F)$

The $B_{\mathrm{t}}$ values at different contact times can be calculated using Eq. (14) for various time intervals. The calculated $B_{\mathrm{t}}$ values were plotted against time $t$.

The Boyd plots are shown in Figs. 4 and 5 for the adsorption of MG and AB onto JSAC, respectively. From these figures, it was clear that the plots were linear for both the adsorbates at all the studied adsorbate concentrations.

Though $r^{2}$ values of both pseudo first-order equation and pseudo second-order equation lie closer to unity, the 


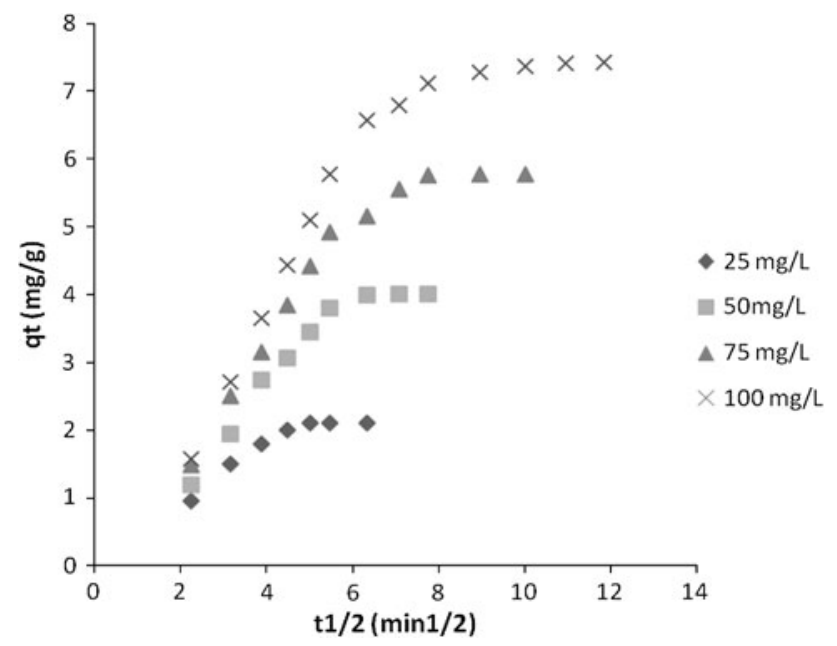

Fig. 3 Intraparticle diffusion model for the adsorption of $\mathrm{AB} 10 \mathrm{~B}$ onto JSAC for $100 \mu \mathrm{m}$ (ads. dosage $=1.5 \mathrm{~g} / 150 \mathrm{ml}$; $\mathrm{pH}$ 2.3; $T=300 \mathrm{~K} ;$ agitation $=150 \mathrm{rpm})$

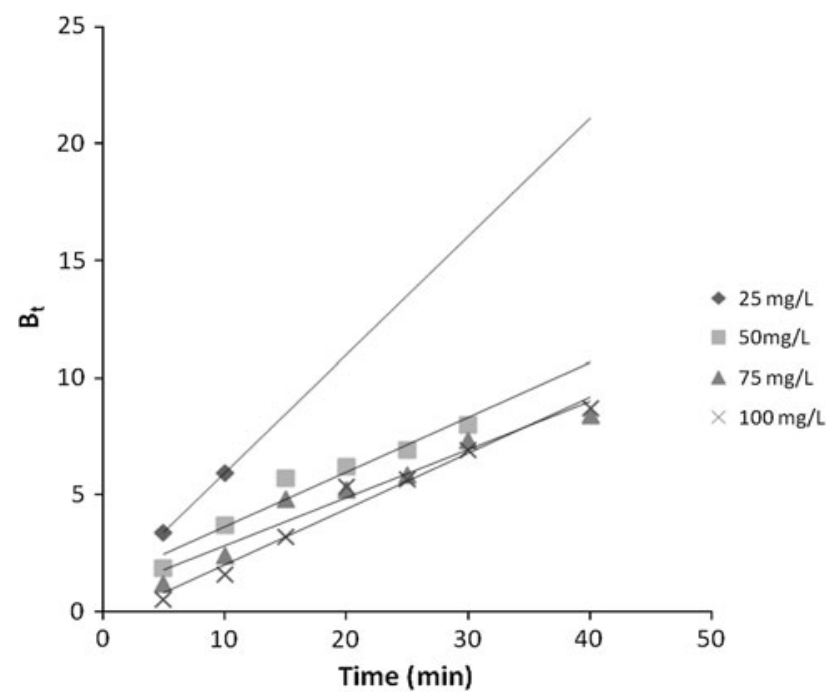

Fig. 4 Boyd plot for the adsorption of MG onto JSAC for $100 \mu \mathrm{m}$ $($ ads. dosage $=1.5 \mathrm{~g} / 150 \mathrm{ml} ; \mathrm{pH} 6.87 ; T=300 \mathrm{~K} ;$ agitation $=$ $150 \mathrm{rpm})$

calculated $q_{\mathrm{e}}$ values of the pseudo first-order equation were not in par with the experimental $q_{\mathrm{e}}$ values. But, in case of pseudo second-order equation, the calculated $q_{\mathrm{e}}$ values are in par with the experimental $q_{\mathrm{e}}$ values. So, it is clear from the accuracy of the model that the adsorption of both the dyes followed pseudo second-order chemical reaction. It was already demonstrated that the pseudo second-order kinetic equation for adsorption is much similar to the universal rate law for a chemical reaction (Liu 2008). Since the processes followed the pseudo second-order equation, it literally suggests that the adsorption is mainly by simple chemical reaction between the dye molecules and the surface functional groups on JSAC. Since JSAC was acid

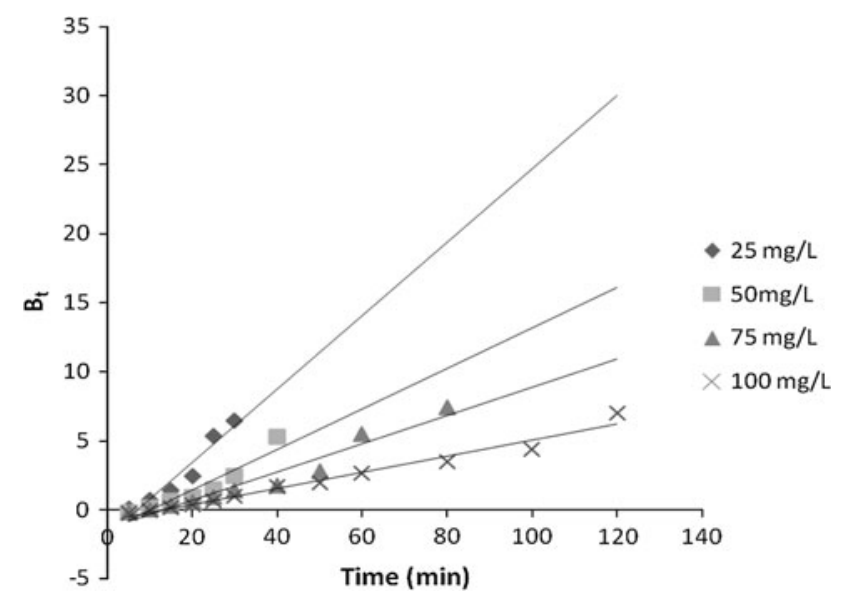

Fig. 5 Boyd plot for the adsorption of AB10B onto JSAC for $100 \mu \mathrm{m}$ (ads. dosage $=1.5 \mathrm{~g} / 150 \mathrm{ml} ; \mathrm{pH} 2.3 ; \quad T=300 \mathrm{~K} ;$ agitation $=$ $150 \mathrm{rpm})$

activated, there may be the presence of some irremovable acid groups on the surface which might have been involved in bonding with the basic dye (MG) molecules which may not be that significant in case of acid dye (AB) molecules.

The plots of the intraparticle diffusion did not pass through the origin indicating that the adsorption processes not only followed the intraparticle diffusion but the film diffusion also played an important role in both the studied adsorption processes. It was also in coincidence with the fact that the processes followed the pseudo second-order model. The fact that film diffusion also played a major role in the studied adsorption processes suggested that the adsorption was mainly by covalent bonding by the surface acidic functional groups. Also, the Boyd plots suggested that the rate-determining step is the external mass transfer since the plots were linear and does not pass through the origin.

Comparison of mechanisms of adsorption of acid dye and basic dye onto JSAC

In general, the mechanism for dye removal by adsorption on a sorbent material may be assumed to involve the following four steps (Cheung et al. 2007): (1) migration of dye from bulk of the solution to the surface of the adsorbent (bulk diffusion); (2) diffusion of dye through the boundary layer to the surface of the adsorbent (film diffusion); (3) transport of the dye from the surface to the interior pores of the particle (intraparticle diffusion or pore diffusion); (4) adsorption of dye at an active site on the surface of material (chemical reaction via ion-exchange, complexation and/or chelation).

The dye sorption is governed usually by either the liquid phase mass transport rate or the intraparticle mass transport rate. Hence diffusive mass transfer is incorporated into the adsorption process. In diffusion studies, the rate can be 
Table 4 Thermodynamic parameters

\begin{tabular}{|c|c|c|c|c|c|c|c|c|c|}
\hline \multirow[t]{2}{*}{ Temperature $(K)$} & \multicolumn{3}{|l|}{$100 \mu \mathrm{m}$} & \multicolumn{3}{|l|}{$600 \mu \mathrm{m}$} & \multicolumn{3}{|l|}{$1,000 \mu \mathrm{m}$} \\
\hline & $\begin{array}{l}\Delta G \\
(\mathrm{~kJ} / \mathrm{mol})\end{array}$ & $\begin{array}{l}\Delta H \\
(\mathrm{~kJ} / \mathrm{mol})\end{array}$ & $\begin{array}{l}\Delta S \\
(\mathrm{~J} / \mathrm{mol} \mathrm{K})\end{array}$ & $\begin{array}{l}\Delta G \\
(\mathrm{~kJ} / \mathrm{mol})\end{array}$ & $\begin{array}{l}\Delta H \\
(\mathrm{~kJ} / \mathrm{mol})\end{array}$ & $\begin{array}{l}\Delta S \\
(\mathrm{~J} / \mathrm{mol} \mathrm{K})\end{array}$ & $\begin{array}{l}\Delta G \\
(\mathrm{~kJ} / \mathrm{mol})\end{array}$ & $\begin{array}{l}\Delta H \\
(\mathrm{~kJ} / \mathrm{mol})\end{array}$ & $\begin{array}{l}\Delta S \\
(\mathrm{~J} / \mathrm{mol} \mathrm{K})\end{array}$ \\
\hline \multicolumn{10}{|c|}{ Adsorption of MG onto JSAC } \\
\hline 293 & -0.223 & & & -0.118 & & & 6.074 & & \\
\hline 300 & -2.724 & 70.322 & 241.61 & -1.921 & 153.53 & 508.85 & 2.697 & 98.746 & 317.448 \\
\hline 313 & -5.221 & & & -4.972 & & & -0.51 & & \\
\hline \multicolumn{10}{|c|}{ Adsorption of $\mathrm{AB} 10 \mathrm{~B}$ onto JSAC } \\
\hline 293 & 2.761 & & & 3.502 & & & 4.986 & & \\
\hline 300 & -0.035 & 53.66 & 175.59 & 1.314 & 52.067 & 166.911 & 0.859 & 71.035 & 226.805 \\
\hline 313 & -1.018 & & & -0.021 & & & 0.253 & & \\
\hline
\end{tabular}

expressed in terms of the square root time. The mathematical dependence of $q_{\mathrm{t}}$ versus $t^{1 / 2}$ is obtained if the process is considered to be influenced by diffusion in the particles and convective diffusion in the solution.

But from Figs. 2 and 3, it was evident that the plots did not pass through the origin, this is indicative of some degree of boundary layer control and these further shows that the intraparticle diffusion is not the sole rate controlling step, but other processes may also control the rate of adsorption. From Fig. 2, for the adsorption of basic dye, MG onto JSAC, one can clearly witness that diffusive mass transfer (first linear portion of the curve) occurred up to the $t^{1 / 2}$ of $3.8 \mathrm{~min}$ which is followed by intraparticle diffusion (second linear portion of the curve). But in case of Fig. 3, for the adsorption of acid dye, AB onto JSAC, the diffusive mass transfer occurred up to the $t^{1 / 2}$ of around $6 \mathrm{~min}$. This suggests that since MG is a basic dye, a sort of chemical reaction occurred between the cationic dye molecules and negatively charged adsorbent surfaces with the aid of the irremovable acidic functional groups in the observed $\mathrm{pH}$. Whereas, since $A B$ is an anionic dye, there is not much intraparticle diffusion due to the presence of some acidic functional groups on the surface of JSAC and hence the \% adsorption also decreased considerably for the adsorption of acid dye onto acid-activated carbon when compared to the basic dye.

It is important to find the slowest step which is the ratedetermining step. It was proved by the Boyd plot that external mass transfer is the rate-determining step for both the adsorbates. But the extent of film diffusion and intraparticle diffusion varied based on the ionic nature of the adsorbates.

\section{Thermodynamic properties}

Thermodynamic parameters which include Gibbs free energy change $(\Delta G)$, enthalpy change $(\Delta H)$ and entropy change $(\Delta S)$ were calculated using Langmuir constant $\left(K_{\mathrm{L}}\right)$.
Thermodynamic parameters obtained are shown in Table 4. From this table, it was evident that the adsorptions of both the dyes were endothermic since the value of $\Delta H$ is positive. Irrespective of the nature of the dyes, the studied adsorption processes were endothermic. Similar results for endothermic adsorption were also observed on adsorption on bentonite (Mall et al. 2005), activated carbon prepared from deoiled soya (Onal et al. 2006), activated carbon prepared from Tuncbilek lignite (Mittal 2006) and hen feathers (Mall et al. 2005). The positive value of $\Delta S$ showed the increased randomness of the adsorbate molecules on the solid surfaces than in the solution for both acid and basic dyes. The adsorption of MG was feasible and spontaneous at all the three temperatures for the adsorbent particle sizes of 100 and $600 \mu \mathrm{m}$ and only at $313 \mathrm{~K}$ for $1,000 \mu \mathrm{m}$ adsorbent particles. However, in the case of $\mathrm{AB}$, it was feasible and spontaneous only for $100 \mu \mathrm{m}$ particle size of the adsorbent at 300 and $313 \mathrm{~K}$. The adsorption of $\mathrm{AB}$ was not feasible at lower temperature and larger adsorbent particles. Hence the thermodynamic studies too suggest that the adsorption of the basic dye, MG onto the acid-activated JSAC was well feasible compared to the acid dye, AB.

\section{Conclusion}

Adsorption studies had been carried out for the removal of Malachite Green (MG) dye and Amido Black 10B (AB) dye by acid-activated carbons derived from $J$. regia shells (JSAC). The $\%$ adsorption of MG dye was maximum at the $\mathrm{pH}$ ranging from 6 to 8 whereas for $\mathrm{AB}$ dye, it was maximum at $\mathrm{pH}$ 2.3. Equilibrium data were tested with Langmuir and Freundlich isotherm model equations. Adsorption of both the dyes followed Freundlich isotherm and hence the prepared activated carbons had heterogeneous surfaces. This heterogeneity was also confirmed by the constants of Redlich-Peterson and Sips isotherms. 
The favorability of the studied adsorption processes were proved by the separation factor $\left(R_{\mathrm{L}}\right)$ of the Langmuir isotherm and the Freundlich exponent $(n)$ of the Freundlich isotherm. The kinetic data were tested with pseudo firstorder and pseudo second-order models. It was concluded that the adsorption of both the dyes followed the pseudo second-order kinetics. The nature and the mechanism of the adsorption processes were studied by employing intraparticle diffusion model and Boyd plot. External mass transfer was the rate-determining step for the adsorption of both the adsorbates. The adsorption is not only by intraparticle diffusion but the film diffusion also played an important role for all three particle sizes with varying initial dye concentrations. The extent of film diffusion and intraparticle diffusion depended on the ionic state of the adsorbates. Thermodynamic analyses showed that both the processes were endothermic in nature and there were increased randomness of the adsorbate molecules on the solid surfaces than in the solution. It was also found that the adsorption of MG dye was much more an efficient process than the adsorption of $\mathrm{AB}$ dye onto JSAC. This may be due to the reason that since JSAC is acid activated; there may be the presence of some irremovable acid groups on the surface of JSAC which would have been involved in formation of covalent bond with the basic dye molecules effectively when compared to the acid dye molecules. The fact that the studied adsorption processes were not only by intraparticle diffusion but the film diffusion also played an important role also suggests the same. From this study, it can be concluded that the acid-activated carbon can be effectively used for the adsorption of basic dyes when compared to the acid dyes. These J. regia shells literally of no economical value, proved to have a great potential in environmental remediation processes.

Acknowledgments The authors are thankful to Council for Scientific and Industrial Research (CSIR), New Delhi, India for providing the necessary funding and facilities to carry out this work.

\section{References}

Abechi ES, Gimba CE, Uzairu A, Kagbu JA (2011) Kinetics of adsorption of methylene blue onto activated carbon prepared from palm kernel shell. Arch Appl Sci Res 3:154-164

Al-Degs YS, El-Barghouthi MI, El-Sheikh AH, Walker GM (2008) Effect of solution $\mathrm{pH}$, ionic strength, and temperature on adsorption behavior of reactive dyes on activated carbon. Dyes Pigments 77:16-23

Balistrieri LS, Murray JW (1981) The surface chemistry of goethite (-FeOOH) in major ion sea water. Am J Sci 281:788-806

Bhatnagar A, Sillanpaa M (2010) Utilization of agro-industrial and municipal waste materials as potential adsorbents for water treatment-a review. Chem Eng J 157:277-296

Boehm HP (1966) Chemical identification of surface groups. Adv Catal 16:179-274
Bulut E, Ozacar M (2008) Adsorption of malachite green onto bentonite: equilibrium and kinetic study and process design. Micropor Mesopor Mat 115:234-246

Cheung WH, Szeto YS, McKay G (2007) Intraparticle diffusion processes during acid dye adsorption onto chitosan. Bioresour Technol 98:2897-2904

El-Sheikh AH, Newman AP, Al-Daffaee HK, Phull S, Cresswell N (2004) Characterization of activated carbon prepared from a single cultivar of Jordanian Olive stones by chemical and physicochemical techniques. J Anal Appl Pyrolysis 71:151-164

Freundlich HMF (1906) Over the adsorption in solution. J Phys Chem 57:385-470

Garg KV, Amita M, Kumar R, Gupta R (2004) Basic dye (methylene blue) removal from simulated wastewater by adsorption using Indian Rosewood sawdust: a timber industry waste. Dyes Pigments 63:243-250

Guo Y, Zhao J, Zhang H, Yang S, Qi J, Wang Z, Xu H (2005) Use of rice husk-based porous carbon for adsorption of Rhodamine B from aqueous solutions. Dyes Pigments 66:123-128

Gupta VK, Mittal A, Krishnan L, Gajbe V (2004) Adsorption kinetics and column operations for the removal and recovery of malachite green from wastewater using bottom ash. Sep Purif Technol 40:87-96

Hameed BH, El-Khaiary MI (2008) Malachite green adsorption by rattan sawdust: isotherm, kinetic and mechanism modeling. J Hazard Mater 159:574-579

Hameed BH, Ahmad AL, Latiff KNA (2007a) Adsorption of basic dye (methylene blue) onto activated carbon prepared from rattan sawdust. Dyes Pigments 75:143-149

Hameed BH, Din ATM, Ahmad AL (2007b) Adsorption of methylene blue onto bamboo-based activated carbon: kinetics and equilibrium studies. J Hazard Mater 141:819-825

Ho S, McKay G (1988) Kinetic models for the sorption of dye from the aqueous solution by wood. Trans IChemE 76:183-191

Langmuir I (1916) The adsorption of gases on plane surface of glass, mica and platinum. J Am Chem Soc 40:1361-1403

Liu Y (2008) New insight to pseudo second-order kinetic equation for adsorption. Colloid Surface A 320:275-278

Mall ID, Srivastava VC, Agarwal NK, Mishra IM (2005) Adsorptive removal of malachite green dye from aqueous solution by bagasse fly ash and activated carbon-kinetic study and equilibrium isotherm analyses. Colloids Surf A: Physicochem Eng Aspects 264:17-28

Mittal A (2006) Adsorption kinetics of removal of a toxic dye, malachite green from waste water using hen feathers. J Hazard Mater B 133:196-202

Namasivayam C, Kavitha D (2002) Removal of Congo red from water by adsorption onto activated carbon prepared from coir pith, an agricultural solid waste. Dyes Pigments 54:47-58

Onal Y, Akmil-Basar C, Eren D, Depci T (2006) Removal of malachite green using carbon-based adsorbents. J Hazard Mater B 128:150-157

Patil S, Renukdas S, Patel N (2011) Removal of methylene blue, a basic dye from aqueous solutions by adsorption using teak tree (Tectona grandis) bark powder. Int J Environ Sci 1:711726

Preethi S, Sivasamy A (2006) Removal of safranin basic dye from aqueous solutions by adsorption onto corncob activated carbon. Ind Eng Chem Res 45:7627-7632

Rengaraj S, Moona SH, Sivabalan R, Arabindoo B, Murugesan V (2002) Removal of phenol from aqueous solution and resin manufacturing industry wastewater using an agricultural waste: rubber seed coat. J Hazard Mater B 89:185-196

Repo E, Kurniawan TA, Warchol JK, Sillanpaa MET (2010) Adsorption of $\mathrm{Co}(\mathrm{II})$ and $\mathrm{Ni}$ (II) on EDTA- and/or DTPA-modified chitosan: kinetic and equilibrium modeling. Chem Eng J 161:73-82 
Repo E, Malinen L, Koivula R, Harjula R, Sillanpaa MET (2011a) Capture of $\mathrm{Co}$ (II) from its aqueous EDTA chelate by DTPAmodified silica gel and chitosan. J Hazard Mater 187:122-132

Repo E, Warchol JK, Bhatnagar A, Sillanpaa MET (2011b) Heavy Metal Adsorption by Novel EDTA-Modified Chitosan-Silica Hybrid Materials. J Colloid Interface Sci 358:261-267

Repo E, Petrus R, Sillanpaa MET, Warchol JK (2011c) Equilibrium studies on the adsorption of $\mathrm{Co}$ (II) and $\mathrm{Ni}$ (II) by modified silica gels: one-component and binary systems. Chem Eng J 172:376-385

Santhy K, Selvapathy P (2006) Removal of reactive dyes from wastewater by adsorption on coir pith activated carbon. Bioresour Technol 97:1329-1336

Senthilkumaar S, Varadarajan PR, Porkodi PK, Subbhuraam CV (2005) Adsorption of methylene blue onto jute fiber carbon: kinetics and equilibrium studies. $\mathrm{J}$ Colloid Interface Sci 284:78-82

Shawabke RA, Rockstraw DA, Bhada RK (2002) Copper and strontium adsorption by a novel carbon material manufactured from pecan shells. Carbon 40:781-786
Tan IAW, Hameed BH, Ahmad AL (2007) Equilibrium and kinetic studies on basic dye adsorption by oil palm fibre activated carbon. Chem Eng J 127:111-119

Tsenga RL, Wub FC, Juang RS (2003) Liquid-phase adsorption of dyes and phenols using pinewood-based activated carbons. Carbon 41:487-495

Vadivelan V, Vasanth Kumar K (2005) Equilibrium, kinetics, mechanism, and process design for the sorption of methylene blue onto rice husk. J Colloid Interface Sci 286:90-100

Vasanth kumar K, Ramamurthi V, Sivanesan S (2005) Modeling the mechanism involved during the sorption of methylene blue onto fly ash. J Colloid Interface Sci 284:14-21

Zhang J, Li Y, Zhang C, Jing Y (2008) Adsorption of malachite green from aqueous solution onto carbon prepared from Arundo donax root. J Hazard Mater 150:774-782

Zhang J, Fu H, Lu X, Tang J, Xu X (2011) Removal of Cu (II) from aqueous solution using the rice husk carbons prepared by the physical activation process. Biomass Bioenerg 35:464-472 